\title{
The Approaches on Assessing the Influence of a Bus Rapid Transit System on Urban Development
}

\author{
Lutfi Prayogi ${ }^{1}$, Yeptadian Sari ${ }^{1}$ \\ ${ }^{1}$ Department of Architecture, Faculty of Engineering, Universitas Muhammadiyah Jakarta, Indonesia \\ lutfi.prayogi@ftumj.ac.id
}

\begin{abstract}
Bus rapid transit (BRT) has been recognized compatible to be built in conjunction with transit-oriented development (TOD). However, little has been explained on how a BRT system may support TOD, including how a BRT system may influence urban development. This article explores the utilized approaches to assessing the influence of a BRT system on urban development under the TOD framework. It explores the justification, methodology, and typical findings of each approach. This article was written through literature review processes that are reviewing the TOD goals and principles and reviewing the utilized approaches. It was found out that there are currently two partially appropriate utilized approaches on assessing the influence of a BRT system on urban development under the TOD framework, that are evaluating the premium brought to properties around the system and assessing the transit ridership change around the system. It was concluded that the two utilized approaches need to be developed, and other new approaches need to be invented.
\end{abstract}

(c) 2019 IJBESR. All rights reserved.

Keywords: Bus rapid transit, urban development, influence, assessment, approaches

\section{Introduction}

Bus rapid transit (BRT) has been recognized compatible to be built in conjunction with transit-oriented development, though the recognition is still limited. Suzuki et al. [1] have explained Curitiba and Ottawa BRT systems' ability to trigger transit-oriented development (TOD) around the systems in recent decades. It should be noted that they argued that BRT systems are 'adaptive': the vehicles can both running wide and frequent. The adaptive characteristics are differentiating BRT systems from rail-based transit systems. Consequently, the adaptive characteristics are also differentiating the TODs triggered by BRT systems from the TODs triggered by rail-based transit systems.

Furthermore, Suzuki et al. [1] also noted that BRT systems' capital and operation costs are lower than rail-based transit systems' ones while they still have performance in par with rail-based transit systems. Their argument is shared by several pieces of research [2-5]. The lower costs make BRT system a viable transit system to be built for triggering transit-oriented development in cities with limited financial resources.

Though there has been a couple of notes on transit-oriented developments occurring around BRT systems [1], little has been explained on how a BRT system may trigger a transitoriented development around the system. Little has been explained on what influence does a BRT system brings that trigger urban development around the system. Furthermore, there is not any solid explanation yet on what kind of BRT system that can trigger urban development around the system. Limited explanation on the mentioned matters hinders 
future development of BRT systems that may properly trigger transit-oriented development around the systems. Better explanation on how a BRT system may trigger transit-oriented development around the system responds to Singh et al. [5a] critics that many current TOD policies are created by assuming that the transit system appropriate for a TOD already provided in the designated TOD area. That situation leads to the less-proper creation of the transit-land use integrated policies, in which the policies are essential for the creation of TODs.

This research intends to explore the approaches to assessing the influence of a BRT system on urban development around the system under the TOD framework. It intends to explore the already utilized approaches. It intends to provide information about the reliability and appropriateness of each approach by exploring the justification, methodology, and typical findings of each approach. By doing so, this research intends to support future researches on how a BRT system may support a TOD around the system and support future developments of BRT systems that may properly trigger TOD around the systems.

\section{Material and Methods}

This research intended to answer the question, "What are the proper ways to assess the influence of a bus rapid transit system on urban development under the transit-oriented development framework?" This research is preliminary research intended to develop some ideas and hypotheses to be developed and examined in further studies. In line with the research intention, a literature review is chosen as the research method considering that it is arguably effective to be used for comprehending the state-of-the-art of the issue stated in the research question.

This article was written through a multi-staged literature review process. The preliminary literature review reviewed the widely acknowledged transit-oriented development (TOD) goals and principles. The findings of this review are used as the framework within which the influence of a bus rapid transit (BRT) system will be discussed. The main literature review reviewed the already utilized approaches in assessing the impact of a BRT system on urban development. Approaches found through this review are discussed concerning their relevance to TOD goals and principles, justification, methodology, and typical findings. Their feasibility is also discussed whenever possible.

It should be noted that the researches quoted and discussed in the primary literature review may not be originally intended to assess the influence of a BRT system on urban development around the system. I quoted those researches by considering at least two things: (1) The researches' relevance to TOD goals and principles and (2) The commonality and repetitiveness of the approaches used in the studies. Furthermore, there may be other research approaches in assessing the influence of the BRT system on urban development under the TOD framework that has not been discussed in this article.

\section{Results and Discussions}

\subsection{Transit-oriented development goals and principles}

Several researchers [6-9] have documented global transit-oriented development (TOD) cases and other cases of a similar concept but having different names. Their works, two of which documented the goals intended to be achieved and principles followed by each development project. Many researchers [10, 10a] have compiled and promoted TOD goals and principles that are partially shared by those development projects. In this sub-section, I will discuss some issues that are commonly concerned, goals that are commonly intended to 
be achieved, and principles that are widely followed on TOD projects.

\subsubsection{Transit system}

The transit system is always discussed by researchers when discussing TOD cases [610b]. All researchers agree that a TOD can only occur in an area with at least one operational transit system. Singh et al. [5a] argued that the design and quality of the transit system are crucial for the success of failure of TOD. Researchers have different preferences in regards to the type of transit system appropriate for a TOD. The differences are stemmed from the distinct characteristics of transit systems: they have different carrying capacity and operational reliability. Earlier discussions on TOD mainly documented TODs triggered by the operation of massive rail transit systems (a system having railcars running on an exclusive right-of-way, either elevated, on-ground, or underground) [6-8]. Recent discussions on TOD, aside from doing the same thing the earlier studies do, also documented TODs triggered by the operation of other transit systems such as bus rapid transit (BRT) [9-10a]. All researches agree that a TOD is a development in which the transit systems play a significant role in the area [6-10a]. The transit systems are utilized optimally: a lot of people are using it daily. The development of the city is triggered, either planned or unplanned, by the operation of the transit systems. Transit planning is inseparable from TOD planning. Mobility planning of the town is heavily based on the operation of the transit systems; the mobility plan of the area relies much on the operation of the transit systems.

\subsubsection{Population density and activity intensity}

Population density and activity intensity are often discussed by researchers when discussing TOD cases [6-10a]. Researchers are paying intention to the number of the population residing and the enormity of activities occurring around transit hubs. It is generally agreed that within TOD areas, more people live close to transit hubs, and fewer people live far from transit hubs. Similarly, more activities occur close to transit hubs, and fewer activities occur far from transit hubs. As have been mentioned in the previous sub-section, more people living and activities occurring close to transit hubs are triggered mainly by the operation of the transit systems instead of by other things. Several researchers [9a-10] noted that the population density and activity intensity around the transit hubs need to be able to support the operation of the transit systems. Furthermore, they pointed out that the population and activity around the transit hubs need to be varied.

\subsubsection{Area connectivity}

Area connectivity is often discussed by researchers when discussing TOD cases [7, 10a]. Researchers' attention on the matter is commonly classified into two issues: the connectivity between the transit hubs and their surrounding area and the interconnectivity between parts of the city. The connectivity between the transit hubs and their surrounding area is crucial for the operation of the transit systems to trigger urban development around the transit hubs, as has been mentioned in the sub-section 'Transit System.' ITDP [10] paid attention to connectivity by walking and cycling. They paid attention to the permeability of the area by walking and cycling: building masses and orientation within the area should provide short-distance trips within the area. Infrastructure for walking and cycling should be provided sufficiently within the area.

\subsubsection{Modal shift}


Transport modal shift is least discussed by researchers when discussing TOD cases [7, 10a]. Cervero [7] found that only a few policy planners and makers in the US targeted a modal share taking place in an area developed under the TOD concept. Nevertheless, he found that TOD and modal share from driving a private motorized vehicle to taking public transit are related. It is the proximity between the developed area around transit hubs, and the transit hubs should trigger the citizens of the area to drive less and take public transit more. ITDP [10] argued that modal share from driving a private motorized vehicle to taking public transportation is a goal to be achieved by a TOD.

\subsection{Utilised approaches in assessing the influence of a bus rapid transit system on urban development}

A lot of researchers have assessed the influence of a bus rapid transit (BRT) system on urban development. Stokenberga [11] provided a review on researches on the influence of a BRT system on property value around the system. Currie and Delbosc [12, 13] and Hensher and Golob [14] researched the influence of BRT systems on transit ridership around the system. In this sub-section, I will quote the mentioned researchers and explore the justification, methodology, and typical findings of each research approach. I will then discuss the approaches in regards to their relevance to TOD goals and principles.

\subsubsection{Influence of a BRT system on property value around the system}

Stokenberga [11] provided a review on researchers on the influence of a BRT system on property value around the system, mostly drawing on Latin American and Asian systems. She noted that urban development takes significant time to be observable. Thus researchers converged their observation on property price change around the BRT systems.
She found cross-sectional approaches as the most frequently used approaches, followed by before-after approaches. She also found that hedonic price regression models commonly complemented before-after approaches. She found researchers often observed and analyzed 'asking price' in their researches. Among the BRT systems analyzed in the literature, Stokenberga found their influence on property price change, not uniform.

Analyzing property price change around BRT systems can be considered relevant to transitoriented development (TOD) goals and principles. Stokenberga quoted Debrezion's argument in her work that the change of the property price shows the change of consumers' willingness to pay for doing activities on the property. An increase in consumers' willingness to pay for the property implies that there is an increase of people who naturally want to do activities on the property. If there is no hindrance besides consumers' ability to pay, more people will do activities on properties close to the BRT systems. Nevertheless, the increase of property value and the growth of people doing activities on the property are not concomitant.

In many cases, hinderances besides consumers' ability to pay do exist. The increase of property value may not coincide with the rise of people doing activities on the property. For instance, land use rule may hinder people from doing activities on a property close to BRT systems even though they are willing to pay to do activities on it.

We can conclude that when researching the influence of a BRT system on urban development around the system under the TOD framework, observing the property price change around the system is partially appropriate. Property price increase around the system shows that TOD may naturally happen around the system. However, TOD may not occur due to various factors. Furthermore, 
Stokenberga [11] noted that such researches utilizing before-after approaches are challenging to be carried out. Such researches utilizing before-after approaches of high validity need to be carried out in years, spanning over several years before and after the provision of the BRT system under observation. Meanwhile, such researches utilizing crosssectional approaches are easier to be carried out.

\subsubsection{Influence of a BRT system on transit ridership around the system}

Currie and Delbosc $[12,13]$ and Hensher and Golob [14] researched the influence of a BRT system on transit ridership around the system, mostly drawing on Australasian systems. They focused their observation on the ridership of buses that used to operate outside the system and then run under the system. They analyzed several measurable ridership features of those buses, including total passenger, passengers per vehicle-trip kilometer (PVK), passengers per route kilometer (PRK), and passengers per hour per direction (PPHPD). They found that almost all of those buses experience increases in total ridership, PVK, PRK, and PPHPD figures after operating under BRT systems. In simple words, nearly all of those buses have more passengers after operating under BRT systems.

Furthermore, they found that a number of those buses' new passengers previously used to drive for the same trip they currently take the bus. It can be concluded from their researches that almost all of the buses currently operating under BRT systems are getting more significance in the area around the systems. The increase of significance of the transit system in the area is one of the TOD goals.

We can conclude that when researching the influence of a BRT system on urban development around the system under the TOD framework, observing the transit ridership change around the system is appropriate. It is worth to note that this approach has also been utilized for researching the influence of a railbased transit system on urban development around the system under the TOD framework, as has been done by Guo et al. [15]. Nevertheless, this approach only addresses one TOD goal, and it does not address the other TOD goals. It should also be noted that the kind of findings of researches carried out by Currie and Delbosc [12, 13] and Hensher and Golob [14] may not clearly show the significance of transit system in the area. The findings, one of which, do not explain the varying importance of other transportation modes in the area. The results show the increase of significance of transit system but do not show the change of sign of different transportation modes in the area.

\section{Conclusion}

While the researches reviewed by Stokenberga, researches carried out by Currie and Delbosc' and Hensher and Golob's may not originally intend to assess the influence of a bus rapid transit (BRT) system on urban development around the system under TOD framework. I argue that the approaches utilized on the former researchers are worthy and eligible to be developed for the following research purpose. The objects being observed on the previous researches are, to a certain extent, relevant to transit-oriented development (TOD) goals and principles. Interpretation of findings of those researches can be used to explain the influence of a BRT system on urban development around the system under the TOD framework. The development of those approaches needs to be carried out so that, for example, the first approach can better show the change of population and activities intensity on properties around the BRT systems. The development also needs to be carried out so that the second approach can better show the general change of significance of transportation modes in the area around the BRT systems. 
Among the four TOD issues discussed in subsection 'Transit-oriented Development Goals and Principles', 'area connectivity' is the one not addressed by the two approaches yet. 'Population density and activity intensity' can be addressed by the first approach while 'transit system' and 'modal shift' can be addressed by the second approach. It seems that a new approach needs to be invented to address the 'area connectivity' issue. Any development to the already utilized approaches and the invention of new approaches need to orient themselves to TOD goals and principles.

\section{Acknowledgement}

This research was funded by Pusat Afiliasi dan Riset Teknologi (Pakarti) Fakultas Teknik Universitas Muhammadiyah Jakarta (FT UMJ).

\section{References}

[1] Suzuki H, Cervero R, Iuchi K. Transforming Cities with Transit: Transit and Land-use Integration for Sustainable Urban Development. Washington, DC, United States: World Bank Group; 2013.

[2] Breiphaupt M, Martins WC, Custodia P, Hook W, McCaul C. The BRT Standard. New York, United States: Institute for Transport and Development Policy; 2014.

[3] Deng T, Nelson JD. Recent developments in bus rapid transit: A review of the literature. Transport Reviews 2011;3(1):69-96.

[4] Racehorse VJ, Parket T, Sussman A, Jian A, Zhang G. Bus rapid transit system development for high quality and cost-effective transit service: A comprehensive review and comparative analysis. IET Intelligent Transport System 2015;9:175-183.

[5] Wirashinghe SC, Kattan L, Rahman MM, Hubbell J, Thilakaratne R, Anowan S. Bus rapid transit - A review. International Journal of Urban Sciences 2013;17:1-31.

[5a] Singh YJ, Zuidgeest MHP, Flacke J, van Maarseveen MFAM. A design framework for measuring transit oriented development. WIT Transactions on the Built Environment 2012;128:719-730.

[6] Calthorpe P. The Next American Metropolis: Ecology, Community, and the American Dream. New York, United States: Princeton Architectural Press; 1993. [7] Cervero R, et al. Transit-oriented Development in the United States: Experiences, Challenges and Prospects. Washington, DC, United States: Transit Development Corporation; 2004.
[8] Cervero R. The Transit Metropolis: A Global Inquiry. Washington, DC, United States: Island Press; 1998.

[9] Curtis C, Renne JL, Bertolini, L. Transit Oriented Development: Making It Happen. Surrey, United Kingdom: Ashgate Publishing; 2009.

[9a] Dittmar H, Poticha S. Defining transit-oriented development: The new regional building block in The New Transit Town - Best Practices in Transit Oriented Development, edited by Dittmar H, Ohland, Gloria. Washington, DC, United States: Island Press; 2004, pp. 19-39.

[10] Institute for Transport and Development Policy. The TOD Standard. New York, United States: Institute for Transport and Development Policy; 2017.

[10a] Newman P, Kenworthy J. Planning for transit oriented development: Strategic Principles in Transit Oriented Development: Making It Happen, edited by Curtis J, Renne JL, Bertolini L. Surrey, United Kingdom: Ashgate Publishing; 2009.

[10b] Hoffman. Transit: Can It Sustain TOD? The Mission Group; 2006.

[11] Stokenberga A. Does bus rapid transit influence urban land development and property values: A review of the literature review. Transport Review 2014;34(3):276-296.

[12] Currie G, Delbosc A. Understanding bus rapid transit route ridership drivers: An empirical study of Australian BRT systems. Transport Policy 2011;16(5):755-764.

[13] Currie G, Delbosc A. Assessing bus rapid transit system performance in Australasia. Research in Transportation Economics 2014;48:142-151.

[14] Hensher DA, Golob TF. Bus rapid transit systems: A comparative assessment. Transportation 2008;35:501518.

[15] Guo J, Nakamura F, Li Q, Zhou Y. Efficienct assessment of transit-oriented development by data envelopment analysis: Case study on the Den-en Toshi Line in Japan. Journal of Advanced Transportation 2018. 